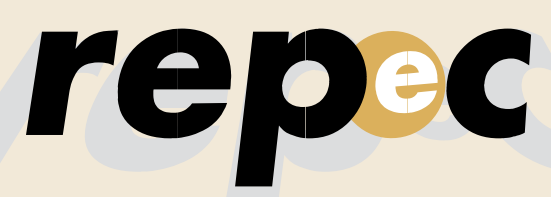

REPeC, Brasília, v. 11, n. 3, art. 1, p. 261-275, jul./set. 2017

Disponivel online em www.repec.org.br

D0l: http://dx.doi.org/10.17524/repec.v11i3.1479
Revista de Educação e Pesquisa em Contabilidade

Journal of Education and Research in Accounting

Periódico Trimestral, digital e gratuito publicado pela Academia Brasileira de Ciências Contábeis

ISSN 1981-8610

\title{
ENADE e Proposta Curricular do CFC: um Estudo em Cursos Brasileiros de Ciências Contábeis
}

\section{Resumo}

Objetivo: este estudo teve o objetivo de avaliar se as instituições que oferecem o curso de Ciências Contábeis com fluxos curriculares mais próximos à proposta curricular do Conselho Federal de Contabilidade (CFC) apresentam maiores notas no ENADE.

Método: na coleta de dados foram visitados os sítios eletrônicos de todos os cursos de Ciências Contábeis participantes do ENADE em 2012, tendo sido localizadas informações de 447 instituições, as quais compuseram a amostra do estudo. $\mathrm{Na}$ análise dos dados foram utilizados: estatística descritiva e o teste de Wilcoxon.

Resultados: os principais achados do estudo demonstram que os currículos acadêmicos das instituições públicas do tipo universidade têm maior proximidade com os conteúdos da proposta do CFC. Os testes ainda evidenciaram que as melhores notas do ENADE do ano de 2012 também foram de IES do tipo universidade, com administração pública.

Contribuições: a pesquisa contribui no sentido de evidenciar que os currículos brasileiros do curso de Ciências Contábeis são bastante divergentes da proposta curricular do CFC. Evidencia também que o maior alinhamento à referida proposta tende a estar associado a maiores notas no ENADE, o que valoriza a proposta enquanto parâmetro para novas revisões curriculares no Brasil.

Palavras-chave: Educação Contábil. Conselho Federal de Contabilidade. Currículo.

\begin{abstract}
Vanessa Ramos da Silva
Mestre em Ciências Contábeis pela Universidade Federal de Uberlândia (UFU) e Professora na Fundação Carmelitana Mário Palmério (FUCAMP). Contato: Rua Geraldo Roberto Gerken, 310, Santa Luzia, Uberlândia/MG, CEP: 38.408-724.

E-mail: vanessaramossilva@hotmail.com

\section{Gilberto José Miranda}

Doutor em Ciências Contábeis pela Universidade de São Paulo (USP) e Professor na Universidade Federal de Uberlândia (UFU). Contato: Av. João Naves de Avila, 2121, Campus Santa Mônica, Bloco F, Sala 1F253, Santa Mônica, Uberlândia/MG, CEP: 38.408-902. E-mail: gilbertojm@ufu.br
\end{abstract}

\section{Janser Moura Pereira}

Doutor em Estatística e Experimentação Agropecuária pela Universidade Federal de Lavras (UFLA) e Professor na Universidade Federal de Uberlândia (UFU). Contato: Av. João Naves de Avila, 2121, Campus Santa Mônica, Bloco F, Sala 1F120, Santa Mônica, Uberlândia/MG, CEP: 38.408-902. E-mail: janser@ufu.br 


\section{Introdução}

As Instituições de Ensino Superior (IES) devem proporcionar o desenvolvimento das competências dos discentes necessárias à atuação profissional. Para isso necessitam de planejamentos adequados do processo de formação, o que se consubstancia no Projeto Político Pedagógico (PPP), documento elaborado com o propósito de estabelecer um planejamento com as principais ideias, elementos, estruturas curriculares e organizacionais de um curso de graduação (Veiga, 2003).

As IES estruturam seus PPP para cada curso, conforme as normatizações das respectivas áreas. As Diretrizes Curriculares Nacionais (DCNs) - Resolução Conselho Nacional de Educação (CNE)/Câmara de Educação Superior (CES) n 10, de 16 de dezembro de 2004, orientam as instituições que oferecem o curso de Ciências Contábeis na elaboração do currículo acadêmico de contabilidade, dividido em três blocos de formação: Básica, Profissional e Teórico-Prática. O Conselho Federal de Contabilidade (CFC) também emitiu, em 2009, uma proposta curricular com a finalidade de auxiliar e padronizar os currículos apresentados pelas IES.

A Contabilidade possui como base legislações que, constantemente, são adaptadas e modificadas. No âmbito internacional, as normatizações são criadas e alteradas com frequência. Seguindo o objetivo de padronizar a forma de fazer Contabilidade, o ensino também precisa de modificações, principalmente nos conteúdos abordados em disciplinas. Aos docentes e às IES, fica a função de adaptar seus planejamentos, métodos e conhecimentos, no intuito de preencher as lacunas e oferecer ensino de Contabilidade, com focos atualizados (Fouché, 2013).

Além dos aspectos acima evidenciados, há de se lembrar das profundas modificações trazidas pela Lei $\mathrm{n}^{\circ} 11.638 / 2007$, ao adotar as International Financial Reporting Standards (IFRS). De acordo com Jackling, Howieson e Natoli (2012), as IFRS impactam no ensino de contabilidade nos países que as adotaram, pois estão relacionadas ao ambiente organizacional que os discentes integrarão, e em alguns casos já estão inseridos. Segundo Carvalho e Salotti (2013), o Brasil é um dos poucos países com adequação completa das IFRS.

Com a heterogeneidade dos currículos apresentada pelas IES brasileiras, programas avaliativos são necessários a fim de garantir a qualidade do ensino ofertado. A Lei no 10.861/2004 instituiu o Sistema Nacional de Avaliação da Educação Superior (SINAES) que estabeleceu três pilares de avaliação das IES: avaliação institucional; avaliação de cursos; e avaliação do desempenho de estudantes. Entre as ferramentas utilizadas pela avaliação está o Exame Nacional de Desempenho de Estudante (ENADE).

A qualidade do ensino de uma instituição é resultado do envolvimento de três componentes: corpo discente, corpo docente e IES (Corbucci, 2007). As variáveis relacionadas ao corpo docente podem interferir no desempenho acadêmico dos alunos, seja pela formação acadêmica ou profissional, estratégia ou método de ensino, regime de trabalho, titulação e experiência profissional. Quanto à IES, as variáveis podem ser classificadas em infraestrutura (ambiente de estudo) e organização didático-pedagógica (forma de ingresso, PPP, tamanho da turma e turno do curso) (Ferreira, 2015). Assim, o resultado da avaliação ENADE representa o desempenho da IES a partir da relação desses três aspectos.

Com base nos rendimentos obtidos pelas IES que ofertam o curso de Ciências Contábeis no ENADE 2012 e conforme o CFC sustenta sobre o fato da desarmonização curricular entre as instituições brasileiras, a questão que orienta este estudo é: a maior proximidade curricular à proposta do Conselho Federal de Contabilidade está associada a maiores níveis de rendimento acadêmico no ENADE? Diante do exposto, o objetivo geral da presente pesquisa é avaliar se as IES que possuem fluxos curriculares mais próximos à proposta do CFC apresentam maiores notas no ENADE dos cursos de Ciências Contábeis.

O objetivo de analisar os currículos das IES e apresentar as relações delas com o desempenho discente nos cursos brasileiros de graduação em Ciências Contábeis se justifica pelo fato de estudos dessa natureza ainda serem incipientes na literatura brasileira consultada. Ademais, a partir de 2008, a Contabilidade brasileira começou a passar por profundas mudanças em virtude da adoção dos padrões internacionais de contabilidade, com a aprovação da Lei no 11.638/2007. Todavia, algumas IESs ainda apresentam currículos anteriores à legislação. Assim, esta pesquisa tem como contribuição prática a possibilidade de auxiliar os gestores de IES que estão em processo de adaptação ou criação de seus currículos e PPP, bem como colaborar com a produção de conhecimentos sobre avaliação das instituições de ensino superior. 


\section{Revisão Teórica}

\subsection{Sistema Nacional de Avaliação da Educação Superior - SINAES}

A finalidade da avaliação se resume no interesse em aprimorar o conhecimento (Grizendi, Silva \& Ferreira, 2008). Para Álvaro Méndez (2002, p. 14), "no âmbito educativo, a avaliação deve ser entendida como atividade crítica de aprendizagem, porque se assume que a avaliação é aprendizagem no sentido de que por meio dela adquirimos conhecimento".

O SINAES possibilita uma avaliação, em todas as IES nacionais, dos cursos de graduação e do rendimento acadêmico dos graduandos, objetivando melhorar a qualidade da educação superior e a ampliação de sua oferta, garantindo os compromissos e responsabilidades sociais das IES (Brasil, 2004). Diante desse propósito, o SINAES, a partir de sua avaliação, caracteriza o perfil da instituição por meio de atividades, projetos, cursos oferecidos, programas e setores. A avaliação se atenta também em apontar as condições das instalações físicas, a qualificação do corpo docente e a estrutura pedagógica às quais os estudantes estão expostos (MEC, 2013).

Em outras palavras, o SINAES avalia os aspectos institucionais, o rendimento acadêmico dos estudantes e o curso de graduação. O ENADE mensura o rendimento dos estudantes, conforme o Art. $5^{\circ}$ da Lei $\mathrm{n}^{\circ}$ 10.861/2004:

$\$ 1^{\circ} \mathrm{O}$ ENADE aferirá o desempenho dos estudantes em relação aos conteúdos programáticos previstos nas diretrizes curriculares do respectivo curso de graduação, suas habilidades para ajustamento às exigências decorrentes da evolução do conhecimento e suas competências para compreender temas exteriores ao âmbito específico de sua profissão, ligados à realidade brasileira e mundial e a outras áreas do conhecimento. $[\ldots]$

$\$ 3^{\circ}$ A periodicidade máxima de aplicação do ENADE aos estudantes de cada curso de graduação será trienal. $\$ 4^{\circ} \mathrm{A}$ aplicação do ENADE será acompanhada de instrumento destinado a levantar o perfil dos estudantes, relevante para a compreensão de seus resultados.

$[\ldots]$

$\$ 8^{\circ} \mathrm{A}$ avaliação do desempenho dos alunos de cada curso no ENADE será expressa por meio de conceitos, ordenados em uma escala com 5 (cinco) níveis, tomando por base padrões mínimos estabelecidos por especialistas das diferentes áreas do conhecimento (Brasil, 2004).

Conforme exposto, o ENADE avalia o rendimento do estudante, mediante competências específicas resultantes da sua formação. De acordo com Polidori, Marinho-Araújo e Barreyro (2006, p. 432), as "expectativas da formação na graduação incluem, para além do domínio de conteúdos, o desenvolvimento de posturas e processos que constituem o desenho de um perfil profissional esperado".

O ENADE é composto por: uma prova constituída de questões que permitem medir o conhecimento e as habilidades; o questionário de impressões dos estudantes sobre a prova; o questionário socioeconômico, que tem o objetivo de caracterizar o perfil do estudante; e o questionário do coordenador(a) do curso (Brasil, 2004). O exame divide os conteúdos em: Formação Geral (25\% da nota) e Formação Específica ( $75 \%$ da nota).

A avaliação de desempenho acadêmico realizada pelo ENADE auxilia as instituições no processo de autoavaliação, para aquelas que buscam melhoria contínua em seus PPPs. Segundo Polidori, Marinho-Araújo e Barreyro (2006, p. 434), o ENADE "pretende proporcionar reflexão no interior do próprio curso e da instituição, na medida em que se constitui como um momento privilegiado de interlocução com os estudantes, visando estimular a reflexão crítica e a avaliação de seus processos formativos".

A aplicação do exame é realizada em todas as IES dos estados brasileiros: 
Entre os objetivos da avaliação constam-se o de conhecer as fortalezas e os problemas da instituição, tratar da adequação de seu trabalho com respeito às demandas sociais, as clássicas e as novas, identificar os graus de envolvimento e os compromissos de seus professores, estudantes e servidores tendo em vista as prioridades institucionais básicas (INEP, 2004, p. 97).

Nesse sentido, o ENADE seria um importante instrumento para a avaliação do processo de ensino e aprendizagem no Brasil, pois, na visão de Worthen, Sander e Fitzpatrick (2004), a avaliação é um veículo de identificação, esclarecimentos e aplicação de critérios defensáveis para determinar valores, qualidade, utilidade e importância do objeto avaliado. Nesse sentido, segundo Peck e Gorzalski (2009) e Preskill e Caracelli (1997), informações provenientes de avaliações de cursos podem contribuir para a melhoria deles ao munirem os gestores de dados que possibilitam conhecimentos mais aprofundados sobre a realidade dos cursos e auxiliem na gestão dos referidos cursos.

A esse respeito, uma análise importante seria a do currículo, que é a ferramenta utilizada pela IES para estruturar a abordagem de conteúdos e suas respectivas cargas horárias na formação do discente. Todavia, existem algumas lacunas nesse processo que dificultam o cumprimento desse papel. De acordo com Rodrigues e Miranda (2013), os coordenadores de cursos não veem os resultados das avaliações como informações relevantes para melhorias nos cursos. Ademais, insta salientar que muitos deles alegam desconhecerem tanto o ENADE quanto o desempenho dos estudantes. Nesse mesmo diapasão, o estudo de Freitas, Barbosa, Galvão \& Miranda (2015) indica que os cursos cujos gestores revelaram uma visão positiva acerca da qualidade e utilidade do Relatório de Curso do ENADE obtiveram notas mais altas na avaliação.

\subsection{O currículo no âmbito dos cursos de Ciências Contábeis}

O processo de planejamento pedagógico, além de permanente, busca o equilíbrio para o desenvolvimento do sistema educacional. De acordo com Ribeiro (2010), a prática educacional no ensino superior está em contínuo movimento, pois não é possível prever para um longo período as necessidades relacionadas à formação acadêmica, por isso os planejamentos do exercício educacional são constantes. Para Silva (1996, p. 23):

O currículo é um dos locais privilegiados onde se entrecruzam saber e poder, representação e domínio, discurso e regulação. É também no currículo que se condensam relações de poder que são cruciais para o processo de formação de subjetividades sociais. Em suma, currículo, poder e identidades sociais estão mutuamente implicados. O currículo corporifica relações sociais (Silva, 1996, p. 23).

Moreira e Silva (1997, p. 28) apontam o currículo como "um terreno de produção e de política cultural, no qual os materiais existentes funcionam como matéria-prima de criação e recriação e, sobretudo, de contestação e transgressão". Por retratar fatores históricos, sociais e culturais, a elaboração de um currículo é "um processo social, no qual convivem lado a lado os fatores lógicos, epistemológicos, intelectuais e determinantes sociais como poder, interesses, conflitos simbólicos e culturais, propósitos de dominação dirigidos por fatores ligados à classe, raça, etnia e gênero" (Jesus, 2008, p. 2640). A esse respeito, Rojas-Rojas e Giraldo-Garcés (2015) destacam a relevância do currículo na transformação das práticas profissionais e dos ambientes nos quais se insere a Contabilidade.

Sacristán (2000, p. 16) apresenta o currículo como um "projeto baseado num plano construído e ordenado, relaciona a conexão entre determinados princípios e uma realização dos mesmos, algo que se há de comprovar e que nessa expressão prática concretiza seu valor". A estrutura do currículo considera as competências e habilidades que devem ser desenvolvidas de forma que o discente participe do processo de construção do conhecimento e que ele não seja visto apenas como um sujeito inativo (Vasconcelos, 2008). 
A programação de uma IES deve considerar "a substantividade e ordenação dos conteúdos do currículo, a configuração das atividades mais adequadas para lograr o que se pretende e a capacidade de realizar esses planos dentro de determinadas condições de espaço, tempo, [...] e estrutura organizativa" (Sacristán, 2000, p. 297). O planejamento do currículo é o ponto inicial para construir o conteúdo em concordância com o contexto de ensino, pensar sobre como será uma sequência antes de realizá-la, considerando tempo disponível, métodos que serão empregados, recursos disponíveis, entre outros (Jackson, 1990; Taylor, 1970).

Diante da composição dos aspectos relacionados ao currículo, seu objetivo é transformar o indivíduo de forma que ele consiga se desenvolver no ambiente relacionado à sua área e seja passível a certas mudanças em sua trajetória (Doll Jr., 1997). Quanto à construção do currículo, o desafio é que proporcione "competência humana integrada na velocidade dos tempos, inclusive para poder humanizar os processos inovadores" (Demo, 1998, p. 30).

Riccio e Sakata (2004, p. 35) comentam que "as instituições de ensino contábil dos diversos países são estimuladas a adequar-se às mudanças provocadas pela globalização". As IES, sejam elas nacionais ou internacionais, diante do efeito de integração, se viram pressionadas a adaptar seus currículos de forma a abranger questões referentes a legislações, organizações e culturas (Kumar \& Usunier, 2001; Kwiek, 2001; Wallace, 2003).

Porter e Carr (1999, p. 565), ao discutirem sobre o ensino de Contabilidade no mundo anglo-americano, ressaltam a "incapacidade dos programas existentes em preparar adequadamente os estudantes para o ambiente dinâmico e complexo dos negócios no qual entram após formados”. Os autores criticam o fato de as IES não fornecerem, aos discentes, métodos necessários para atuarem no mercado de trabalho, pois muitas vezes trabalham apenas conceitos e não os auxiliam a desenvolverem suas competências.

Os currículos das instituições brasileiras possuem como regulamentação norteadora a Resolução CNE/CES no 10/2004, que institui as DCNs para os cursos de graduação em Ciências Contábeis. Com a autonomia e flexibilidade, as IES devem considerar que quanto maior o oferecimento ao graduando de ferramentas para desenvolver suas competências no período acadêmico, no tocante à estrutura do currículo, melhor serão seus desempenhos e sucesso profissional (Paola, 2009). Pires e Ott (2008, p. 7) destacam que:

As determinações da Resolução CNE/CES n. 10/2004 são amplas e flexíveis o que significa que cabe a cada IES definir, por exemplo, quais as disciplinas a serem ministradas e o número de horas-aula destinadas a cada conteúdo, desde que as diretrizes estabelecidas sejam observadas, ou seja, desde que os conteúdos curriculares sejam contemplados (Pires; Ott, 2008, p. 7).

Conforme citado pela Resolução $n^{\circ}$ 10/2004, a graduação em Ciências Contábeis possui inter-relação com outros ramos do conhecimento como Administração, Economia, Matemática e outros. Desta forma, as disciplinas de áreas afins e complementares contribuem com a formação contábil (Lagioia, Santiago, Gomes, \& Ribeiro Filho, 2007). A ponderação feita pelos autores Capacchi, Moretto, Vancin \& Padilha (2007, p. 12) é "se não se está formando pessoas muito generalistas, que na realidade sabem um pouco de tudo e nada com profundidade frente ao profissionalismo que é tão esperado pelos empresários".

Sobre essa liberdade de abordagem dos currículos dos cursos de Ciências Contábeis, os autores Capacchi et al. (2007) analisaram em sua pesquisa a estrutura curricular e os desafios na formação dos cursos de Ciências Contábeis das universidades do Rio Grande do Sul. Em seus achados, os autores verificaram que nos cursos analisados, os currículos abordam um número reduzido de conteúdos específicos da área contábil e concluíram então que para as instituições pesquisadas, a formação era generalista e, não, especialista, logo, poderia interferir nos resultados desses discentes, em exames da área e em processos seletivos no meio profissional.

Galdino e Soares (2013, p. 2) investigaram se "a formação em Ciências Contábeis pelas universidades públicas da região norte do Brasil é predominantemente generalista ou especialista”. Sete IES compuseram a amostra do estudo e as análises foram realizadas apenas nas disciplinas obrigatórias dos currículos, separadas por "disciplinas contábeis" e "disciplinas não contábeis". Os autores não conseguiram afirmar se a formação era, predominantemente, especialista ou generalista, devido à proximidade dos percentuais encontrados. 
De acordo com Soares, Borgert, Pfitscher \& Will (2012) na literatura especializada, currículos especialistas ou generalistas recebem diferentes tratamentos, esses conceitos seguem distintos argumentos, porém apropriados. De maneira resumida, os autores discutem que o formato generalista tem como principal característica os currículos com diversidades de conteúdos, seguindo a formação social e profissional. Já o currículo especialista tem o objetivo de penetrar e analisar, de modo mais profundo, tópicos específicos da Contabilidade, preparando assim um profissional especializado, em determinados segmentos da área.

O CFC destacou que, no ano de 2009, existiam mais de 1.000 currículos para o curso de Ciências Contábeis, dificultando a padronização nacional de conteúdo, ementa e bibliografia (CFC, 2009). Assim, emitiu uma Proposta Nacional de Conteúdo para o curso de Graduação em Ciências Contábeis, abrangendo:

O perfil profissional esperado para o formando, em termos de competências e habilidades;

Os componentes curriculares integrantes;

Os sistemas de avaliação do estudante e do curso;

O estágio curricular supervisionado; as atividades complementares;

A monografia, o projeto de iniciação científica ou projeto de atividade como componente opcional da instituição; $\mathrm{e}$

O regime acadêmico de oferta (CFC, 2009, p. 19).

A percepção dos discentes sobre as disciplinas do curso de Ciências Contábeis da Universidade Federal do Paraná foi analisada por Corrêa, Antonovz e Espejo (2009). Os achados demonstraram que os conteúdos relacionados à Administração, Economia, Informática e Matemática não contribuem para a formação desses estudantes, além de classificarem a disciplina relacionada ao conteúdo Ética como pouco importante. Outra análise sobre conteúdos curriculares foi feita pela pesquisa de Rodrigues e Miranda (2013), com o foco em conteúdos mais presentes nos concursos brasileiros para o cargo de Contador, nos anos de 2011 e 2012, os quais identificaram um desacordo entre as sugestões curriculares da Resolução $\mathrm{n}^{\circ} 10 / 2004$, o CFC e o exigido pelas provas analisadas.

Oliveira, Silva, Miranda \& Tavares $(2015$, p. 1) realizaram uma análise comparativa do nível de aderência dos currículos com a proposta curricular do CFC em Instituições Federais de Ensino Superior (Ifes) no Brasil. A comparação foi realizada com os blocos de conteúdos apresentados na proposta com as ementas curriculares das IFES. Os autores observaram que 55\% das instituições analisadas aderem ao conteúdo proposto pelo Conselho. As disciplinas optativas tiveram menor aderência, já os conteúdos do bloco de formação teórico-prática apresentaram o maior nível de aderência, mesmo com uma diferença pequena entre a média de adoção entre as regiões. O Centro-Oeste foi a região com maior nível de aderência (61\%).

Em outro estudo, Silva e Miranda (2016) realizaram análise curricular do curso de Ciências Contábeis em 447 IES brasileiras. Os autores diagnosticaram que quanto maiores as cargas horárias destinadas pelas instituições às disciplinas de formação básica, menor tenderiam ser os rendimentos dos discentes no ENA$\mathrm{DE}$, considerando que $75 \%$ do exame aborda questões referentes aos conteúdos de formação profissional.

A despeito dos estudos já realizados, algumas lacunas ainda prevalecem, como por exemplo, identificar se as instituições que possuem currículos mais alinhados à formação profissional teriam maiores notas no ENADE.

\section{Metodologia}

A pesquisa se classifica como descritiva, cuja abordagem é caracterizada como quali-quanti, devido a seu enfoque de tratamento estatístico dos dados, bem como a análise e interpretação de conteúdos. De acordo com Richardson (2011, p. 79), os dois métodos estão relacionados e "o aspecto qualitativo de uma investigação pode estar presente até mesmo nas informações colhidas por estudos essencialmente quantitativos". Em relação aos procedimentos de coleta de dados foi utilizada a pesquisa documental. 
A população é composta por IES de categoria administrativa pública e privada, que ofertaram o curso de Ciências Contábeis e receberam conceito ENADE em 2012, relacionadas na Planilha de Conceito Preliminar do Curso (CPC) do ano de 2012, disponibilizada no site do Inep (2012). No total, eram 995 IES, porém as instituições que não apresentaram a nota do concluinte no ENADE 2012 foram descartadas. Com isso, a população foi reduzida para 854 IES. Pesquisou-se o currículo acadêmico de todas as IES, em seus respectivos sites, o período de busca nos mesmos e para envio das solicitações por e-mail, foi de abril a julho de 2015. Foram coletados 589 currículos, no entanto, 142 IES não divulgaram as cargas horárias por disciplina; assim, a amostra ficou composta por 447 IES.

Inicialmente, foram feitas as análises descritivas da amostra com o objetivo de caracterizá-la. Posteriormente, os conteúdos dos currículos das IES participantes da amostra foram classificados de acordo com a proposta de Silva (2016), considerando-se a Resolução CNE/CES n 10/2004, a Proposta Curricular do CFC e o estudo realizado por Rodrigues e Miranda (2013), conforme exposto na primeira coluna da Tabela 1.

Diante da autonomia de cada IES para a construção de seus currículos, algumas disciplinas encontradas não tinham sido citadas pela Proposta Curricular do CFC ou pela Resolução CNE/CES no 10/2004. Com isso, dois grupos classificaram estes conteúdos: G19 (Outras disciplinas básicas), compostos por disciplinas como Metodologia de Pesquisa, Psicologia, Sociologia, Língua Portuguesa, Comunicação e Língua Estrangeira; e o G20 (NC) com os conteúdos não classificados nos outros grupos ou pela Resolução $n^{\circ}$ 10/2004 e a Proposta do CFC, pois algumas instituições apresentaram disciplinas relacionadas a temas religiosos e práticas desportivas.

Dentro da estatística descritiva, utilizou-se o Coeficiente de Variação (CV) Segundo Martins e Theóphilo (2007) é uma medida de dispersão, resultado da divisão do Desvio Padrão Amostral (S) pela Média Amostral $(\bar{X})$. Para análise do CV, os autores sugerem: (a) CV < 15\%: representa baixa dispersão; (b) $15 \%$ $<\mathrm{CV}<30 \%$ : representa média dispersão; e (c) $\mathrm{CV} \geq 30 \%$ : representa elevada dispersão.

Também foi aplicado o teste de Wilcoxon para avaliar se existe diferença significativa referente aos fatores Região Brasileira, Categoria Administrativa e Organização Acadêmica em relação as variáveis dos 20 grupos de conteúdos. Cabe ressaltar que as análises foram implementadas no freeware $R$ ( $R$ Development Core Team, 2015).

\section{Resultados}

\subsection{Análise descritiva dos dados}

Todos os 26 estados brasileiros e o Distrito Federal fizeram parte da amostra. Os estados que apresentaram maior número de currículos foram: Rio Grande do Sul (RS) - 41; Santa Catarina (SC) - 43; Minas Gerais (MG) e Paraná (PR) - 51; e São Paulo (SP) - 66. Da região Sudeste, foram analisados 147 currículos, e da região Sul, 135. Juntas, elas representaram $63 \%$ da amostra total. Já da região Nordeste foram examinados 80 currículos; da região Centro-Oeste 50 e da região Norte, 35. Nesse sentido, a amostra retrata o fato de que as regiões Sul e Sudeste concentram as maiores quantidades de instituições com o curso de Ciências Contábeis no País.

As IES são classificadas pelo Inep em duas Categorias Administrativas: Públicas e Privadas. Examinando-se o banco de dados, nota-se que a amostra está dividida em $80,8 \%$ de instituições privadas e $19,2 \%$ de IES públicas. Nesse aspecto também, a amostragem reflete a composição da população, isto é, em torno de $80 \%$ de instituições de ensino na rede particular.

A caracterização que o Inep realiza de cada IES identifica também o tipo da Organização Acadêmica, divididas em: Universidades, Centros Universitários, Faculdades e Institutos Federais de Educação, Ciência e Tecnologia. Nesta amostra, 239 instituições são faculdades, 145 universidades e 63 centros universitários. 
A Tabela 1, a seguir, apresenta a estatística descritiva da carga horária dos grupos de conteúdos pesquisados.

Tabela 1

Estatística Descritiva da Carga Horária dos Grupos de Conteúdos, 2015

\begin{tabular}{|c|c|c|c|c|c|c|}
\hline Grupos & Proposta CFC & Mínima & Máxima & Média & Mediana & CV \\
\hline G1 - Teorias da Contabilidade & 180 & 40 & 340 & 149,84 & 144 & 46,176 \\
\hline G2 - Contabilidade Gerencial & 360 & 120 & 380 & 425,98 & 420 & 110,244 \\
\hline $\begin{array}{l}\text { G3 - Noções de Quantificações } \\
\text { Financeiras }\end{array}$ & 120 & 0 & 440 & 59,84 & 60 & 63,275 \\
\hline G4 - Finanças e Contabilidade Pública & 180 & 0 & 240 & 98,93 & 80 & 38,049 \\
\hline $\begin{array}{l}\text { G5 - Auditoria; Perícia e Arbitragem; } \\
\text { Atuarial }\end{array}$ & 150 & 0 & 400 & 193,68 & 180 & 55,145 \\
\hline $\begin{array}{l}\text { G6 - Contabilidade Societária, } \\
\text { Avançada e Internacional }\end{array}$ & 390 & 60 & 576 & 290,75 & 288 & 87,734 \\
\hline $\begin{array}{l}\text { G7 - Planejamento e Contabilidade } \\
\text { Tributária }\end{array}$ & 60 & 0 & 360 & 112,59 & 120 & 51,325 \\
\hline G8 - Contabilidade Aplicada & 0 & 0 & 340 & 83,02 & 72 & 73,145 \\
\hline G9 - Responsabilidade Social & 120 & 0 & 520 & 65,09 & 60 & 45,632 \\
\hline G10 - Administração & 60 & 0 & 660 & 186,86 & 160 & 107,951 \\
\hline G11 - Economia & 90 & 0 & 384 & 104,39 & 80 & 51,349 \\
\hline G12 - Direito & 270 & 50 & 630 & 209,59 & 204 & 71,301 \\
\hline G13 - Métodos Quantitativos & 210 & 80 & 557 & 234,30 & 240 & 64,989 \\
\hline G14 - Estágio & 180 & 0 & 744 & 198,67 & 204 & 144,975 \\
\hline G15 - Atividades complementares & 60 & 0 & 1024 & 184,21 & 180 & 150,614 \\
\hline G16 - Disciplinas Optativas & 120 & 0 & 840 & 89,03 & 60 & 118,495 \\
\hline G17 - Laboratórios & 120 & 0 & 620 & 164,26 & 152 & 97,978 \\
\hline $\begin{array}{l}\text { G18 - Trabalho de Conclusão de } \\
\text { Curso }\end{array}$ & 120 & 0 & 624 & 101,34 & 80 & 100,036 \\
\hline G19 - Outras Disciplinas Básicas & 210 & 0 & 483 & 226,72 & 240 & 87,625 \\
\hline $\begin{array}{l}\text { G20 - Conteúdos não presentes na } \\
\text { Proposta CFC }\end{array}$ & 0 & 0 & 756 & 40,28 & 0 & 82,867 \\
\hline
\end{tabular}

Legenda: CV: Coeficiente de Variação

Fonte: elaborada pelos autores.

Nota-se que somente cinco grupos tiveram carga horária mínima diferente de zero: G1 (Teorias da Contabilidade), G2 (Contabilidade Gerencial), G6 (Contabilidade Societária, Avançada e Internacional), G12 (Direito) e G13 (Quantitativo). Além dos três grupos relacionados com a contabilidade (G1, G2 e G6), as disciplinas que abordam conteúdos sobre Direito e Métodos Quantitativos foram consideradas, por todas as IES da amostra, como necessárias para a formação básica do profissional contábil.

A Tabela 1 demonstra que metade das instituições da amostra disponibiliza, no mínimo, 420 horas em seus currículos para as disciplinas relacionadas à área da Contabilidade, listadas no grupo G2 (Contabilidade Gerencial). O grupo G6 (Contabilidade Societária, Avançada e Internacional) também apresentou um alto valor para a mediana: 288 horas mínimas nos currículos de metade das IES pesquisadas. Isso é justificável, pois os conteúdos classificados nesse grupo estão relacionados com as principais disciplinas de Contabilidade. Assim a recorrência de questões pertinentes a essa abordagem tende a ser mais frequente nos exames de avaliação do rendimento acadêmico dos alunos de Ciências Contábeis. 
A mediana foi de 72 horas para o grupo G8 (Contabilidade Aplicada), e as disciplinas deste grupo voltam-se para conteúdos aplicados a determinados setores da economia. O grupo G4 (Finanças e Contabilidade Pública), também com abordagem específica, nesse caso no Setor Público, apresentou carga horária mínima de 80 para $50 \%$ das IES.

$\mathrm{Na}$ Tabela 1, todos os grupos apresentaram coeficientes de variação maiores que $30 \%$, ou seja, todos estão com alta dispersão (Martins \& Theóphilo, 2007). O G4 (Finanças e Contabilidade Pública) apresentou o menor coeficiente em relação aos outros grupos (38,049\%) e quase todos os grupos do "Bloco de Formação Teórico-Prática” passaram do nível 100\% de dispersão relativa: G14 (Estágio), G15 (Atividades complementares), G16 (Optativas) e G18 (TCC). Somente o G17 (Laboratório) apresentou uma dispersão relativa menor, 97,978, mas não muito distante de 100 . Ou seja, existe grande heterogeneidade no tocante à carga-horária destinada a cada grupo de conteúdos entre as IES brasileiras que ofertam o curso de Ciências Contábeis.

Esse resultado confirma a heterogeneidade dos currículos no território nacional preconizada pelo Conselho Federal de Contabilidade (CFC, 2009), o que, por um lado, pode ser positivo no sentido de privilegiar diferenças regionais, mas, por outro, dificulta intercâmbios entre alunos e podem ter reflexos em avaliações amplas como ENADE e Exame de Suficiência.

\subsection{Relações entre ENADE (2012), os currículos pesquisados e a proposta curricular do Conselho Federal de Contabilidade}

As cargas horárias presentes na proposta nacional de conteúdo para o curso de graduação em Ciências Contábeis pelo CFC, em 2009, foram comparadas com as médias das IES investigadas relativas aos 20 grupos de conteúdo analisados. O CFC (2009) destaca que, até o ano da publicação da proposta, mais de 1.000 cursos de Contabilidade tinham currículos diferentes e isso "dificulta não só os estudantes em termos de transferências, como também a oferta de um ensino mais harmonioso em termos de conteúdo, ementário e bibliografia" (CFC, 2009, p. 5).

Para comparar as cargas horárias destinadas pelas IES para cada um dos grupos de conteúdos, considerando-se categoria administrativa, organização acadêmica e região, executou-se o teste de Wilcoxon. 
Tabela 2

Teste Wilcoxon: Categoria Administrativa, Organização Acadêmica e Região versus Proposta Curricular do Conselho Federal de Contabilidade, 2015

\begin{tabular}{|c|c|c|c|c|c|c|c|}
\hline \multirow[b]{2}{*}{ Grupos } & \multirow{2}{*}{$\begin{array}{l}\text { Todas } \\
\text { IES }\end{array}$} & \multicolumn{2}{|c|}{ Categoria Administrativa } & \multicolumn{2}{|c|}{ Organização Acadêmica } & \multicolumn{2}{|c|}{ Região Brasileira } \\
\hline & & Pública & Privada & Universidade & $\begin{array}{l}\text { Centro Univ. e } \\
\text { Faculdade }\end{array}$ & SUL e SE & $\mathrm{CO}, \mathrm{NO}$ e $\mathrm{NE}$ \\
\hline G1 & 0,0000 & 0,0008 & 0,0000 & 0,0000 & 0,0000 & 0,0000 & 0,0000 \\
\hline $\mathrm{G} 2$ & 0,0000 & 0,0005 & 0,0000 & 0,0000 & 0,0000 & 0,0000 & 0,0000 \\
\hline G3 & 0,0000 & 0,0000 & 0,0000 & 0,0000 & 0,0000 & 0,0000 & 0,0000 \\
\hline G4 & 0,0000 & 0,0000 & 0,0000 & 0,0000 & 0,0000 & 0,0000 & 0,0000 \\
\hline G5 & 0,0000 & 0,0000 & 0,0000 & 0,0000 & 0,0000 & 0,0000 & 0,0000 \\
\hline G6 & 0,0000 & 0,0000 & 0,0000 & 0,0000 & 0,0000 & 0,0000 & 0,0000 \\
\hline G7 & 0,0000 & 0,0000 & 0,0000 & 0,0000 & 0,0000 & 0,0000 & 0,0000 \\
\hline G8 & 0,0000 & 0,0000 & 0,0000 & 0,0000 & 0,0000 & 0,0000 & 0,0000 \\
\hline G9 & 0,0000 & 0,0000 & 0,0000 & 0,0000 & 0,0000 & 0,0000 & 0,0000 \\
\hline G10 & 0,0000 & 0,0000 & 0,0000 & 0,0000 & 0,0000 & 0,0000 & 0,0000 \\
\hline G11 & 0,0000 & 0,0274 & 0,0004 & 0,0013 & 0,0051 & 0,0002 & 0,0444 \\
\hline G12 & 0,0000 & 0,0000 & 0,0000 & 0,0000 & 0,0000 & 0,0000 & 0,0000 \\
\hline G13 & 0,0000 & 0,0043 & 0,0000 & 0,0224 & 0,0000 & 0,0000 & 0,0005 \\
\hline G14 & 0,0518 & 0,4130 & 0,0726 & 0,7396 & 0,0224 & 0,0285 & 0,7383 \\
\hline G15 & 0,0000 & 0,0000 & 0,0000 & 0,0000 & 0,0000 & 0,0000 & 0,0000 \\
\hline G16 & 0,0000 & 0,8977 & 0,0000 & 0,2289 & 0,0000 & 0,0000 & 0,0000 \\
\hline G17 & 0,0000 & 0,0456 & 0,0000 & 0,0755 & 0,0000 & 0,0000 & 0,0000 \\
\hline G18 & 0,0000 & 0,2038 & 0,0000 & 0,7645 & 0,0000 & 0,0001 & 0,0000 \\
\hline G19 & 0,0000 & 0,4962 & 0,0000 & 0,0794 & 0,0000 & 0,0533 & 0,0000 \\
\hline G20 & 0,0000 & 0,0007 & 0,0000 & 0,0000 & 0,0000 & 0,0000 & 0,0000 \\
\hline
\end{tabular}

Legenda: CO - Centro Oeste; NE - Nordeste; NO - Norte; SE - Sudeste; Centro Univ. - Centro Universitário.

Fonte: Freeware R.

Quando se compara as medianas da amostra pesquisada por grupo de conteúdos com as cargas horárias constantes na proposta curricular do CFC, nota-se que, em geral, as cargas horárias das instituições pesquisadas são estatisticamente diferentes da proposta, a única exceção foi o grupo G14 (Estágio Supervisionado). Ou seja, em uma análise geral, este é o grupo de conteúdos cujas cargas horárias das IES brasileiras mais se aproximam da proposta curricular do CFC.

Quando se observa a categoria administrativa das IES pesquisadas, nota-se que, além do grupo G14 (Estágio Supervisionado), os grupos G16 (Optativas), G18 (TCC) e G19 (Outras disciplinas básicas), nas instituições públicas, também não possuem cargas horárias estatisticamente diferentes da proposta curricular do CFC. Todavia, com exceção do grupo G14 (Estágio Supervisionado), todos os outros grupos de conteúdo das IES privadas da amostra são diferentes estatisticamente da proposta do CFC.

Uma análise semelhante pode ser feita quando se observa a organização acadêmica das instituições pesquisadas. Neste caso, os grupos acima citados (G14, G16, G18 e G19), e também o grupo G17 (Laboratório) das universidades não apresentaram diferenças significativas ao se comparar as cargas horárias dos cursos pesquisados com a proposta curricular do Conselho Federal de Contabilidade. Portanto, os currículos das universidades se aproximam mais da proposta do CFC que os de centros universitários e faculdades. 
No tocante à região de localização das instituições, o grupo G14 (Estágio Supervisionado) nas regiões Norte, Nordeste e Centro-Oeste, bem como o grupo G19 (Outras Disciplinas Básicas), nas regiões Sul e Sudeste, não tiveram diferenças significativas de cargas horárias da proposta curricular do CFC. Isso reflete a declaração feita pelo próprio CFC em sua proposta, os quais criticavam a diversidade dos currículos entre as IES nacionais e defendiam a harmonização de conteúdos curriculares.

A seguir, os resultados do teste de médias das cargas horárias são apresentados na Tabela 3 .

Tabela 3

Teste de Médias Wilcoxon por tipo de Categoria Administrativa, Instituição e Região Brasileira, 2015

\begin{tabular}{lcccccc}
\hline & \multicolumn{2}{c}{ Categoria Administrativa } & \multicolumn{2}{c}{ Organização Acadêmica } & \multicolumn{2}{c}{ Região Brasileira } \\
\hline & Pública & Privada & Universidade & $\begin{array}{c}\text { Centro Univ. e } \\
\text { Faculdade }\end{array}$ & SUL e SE & CO, NO e NE \\
\hline $\mathrm{N}$ & 86 & 361 & 145 & 302 & 282 & 165 \\
\hline Média Ranks & 282,50 & 210,06 & 280,83 & 196,72 & 250,85 & 178,12 \\
\hline Wilcoxon & 10492 & & 13655 & 15694 \\
\hline p-valor & $<0,000$ & & $<0,000$ & $<0,000$ \\
\hline
\end{tabular}

Legenda: CO - Centro Oeste.

NE - Nordeste.

NO - Norte.

SE - Sudeste.

Centro Univ. - Centro Universitário.

Fonte: Freeware R.

O teste Wilcoxon também revela que o rendimento acadêmico medido pela nota ENADE das instituições pesquisadas é superior nas categorias: Universidades, Públicas e regiões Sul e Sudeste, ou seja, exatamente as instituições que possuem currículos mais próximos da proposta do CFC, conforme teste de Wilcoxon. Na amostra existem 275 IES privadas a mais que as públicas. Portanto, na maioria das instituições, os currículos não estão alinhados com a proposta do CFC de 2009. No entanto, os estados das regiões Sul e Sudeste, que concentram 63\% da amostra, tendem a estruturar seus currículos mais alinhados com a proposta do CFC.

$\mathrm{Na}$ Pesquisa de Silva e Miranda (2016), foi evidenciado que as instituições que privilegiam conteúdos profissionais tendem a apresentar maiores resultados no ENADE, o que seria justificável, uma vez que 75\% do conteúdo do referido exame é de natureza profissional. A esse respeito é importante salientar que na proposta curricular do Conselho Federal de Contabilidade predominam os conteúdos de natureza profissional.

\section{Considerações Finais}

O objetivo geral da presente pesquisa foi verificar se as IES brasileiras com currículos acadêmicos mais semelhantes à Proposta Curricular do CFC (2009) obtiveram maiores rendimentos no ENADE 2012.

A Resolução CNE/CES n 10/2004 entrou em vigor três anos antes da implementação da Lei no 11.638/2007, legislação que alterou o cenário da Contabilidade brasileira em virtude da adoção aos padrões internacionais, ou seja, os aspectos relacionados aos conteúdos profissionais da contabilidade passaram por adaptações. Considerando que essa é a principal vertente de avaliação do ENADE, mesmo que os currículos das IES estejam próximos à proposta da resolução, as instituições conseguem manter os conteúdos atualizados devido à flexibilidade e autonomia que as IES possuem para a definição dos currículos. 
Nessa linha de entendimento, sob o argumento da diversidade curricular no Brasil que foi constatada neste estudo, o CFC emitiu, em 2009, a Proposta Curricular para os cursos de Ciências Contábeis. Os resultados demonstraram baixa aderência à referida proposta, pois apenas alguns grupos de conteúdos, em alguns tipos específicos de instituições, não apresentaram cargas horárias estatisticamente diferentes da proposta. As proximidades ocorreram, na maioria, em instituições públicas do tipo "universidade". Os testes também revelaram que são estas as instituições que possuem, também, as maiores notas no ENADE. Estes resultados sugerem que as instituições que possuem currículos mais similares à proposta do CFC tendem a apresentar maiores rendimentos no ENADE.

Os dados também revelaram que muitas instituições apresentaram cargas elevadas de disciplinas de conteúdos básicos em detrimentos de conteúdos profissionais. Uma hipótese para tanto seria o aproveitamento de professores em disciplinas compartilhadas entre cursos, como Administração e Ciências Contábeis. Cabe lembrar que $75 \%$ das questões avaliadas no ENADE se referem a conteúdos profissionais. Assim, as instituições que possuem currículos com maior foco nos conteúdos profissionais tendem a apresentar maiores notas no ENADE. Da mesma forma, as instituições que privilegiam conteúdos profissionais também se aproximam mais da Proposta Curricular do CFC.

Mas é importante lembrar que a formação focada, exclusivamente, nos conteúdos profissionais pode implicar a formação de profissionais com conhecimentos e habilidades voltadas basicamente para os aspectos técnicos da profissão, a chamada formação especialista (Capacchi et al. 2007; Soares et al., 2012). Todavia, no cenário atual, além do conhecimento profissional o currículo deve contribuir com o desenvolvimento de habilidades, como pensamento crítico, capacidade de trabalho em grupo, entre outras características fundamentais na formação do contador para atuação no mundo globalizado, conforme Rojas-Rojas e Giraldo-Garcés (2015), o ensino contábil deve provocar mudanças sobre aspectos sociais e humanos na comunidade contábil.

Quando se avalia o rendimento acadêmico tendo por base o ENADE, é preciso deixar claro que diversas outras variáveis afetam este indicador. São outros atributos das instituições de ensino características dos professores e, principalmente, dos discentes (Miranda, Lemos, Oliveira, \& Ferreira, 2015).

Entre as contribuições desse estudo, cabe destacar que, no tocante à carga horária dos conteúdos, os currículos brasileiros do curso de Ciências Contábeis são bastante divergentes da proposta curricular CFC. No entanto, o maior alinhamento à referida proposta tende a estar associado a maiores notas no ENADE, o que valoriza a proposta enquanto parâmetro para novas revisões curriculares.

Para estudos futuros, sugere-se investigar se a maior proximidade curricular da proposta do CFC está associada a maiores rendimentos no Exame de Suficiência em Contabilidade. Conforme o resultado encontrado, será possível realizar um comparativo entre a abordagem do exame aplicado pelo Conselho da classe contábil com a prova elaborada pelo MEC para os estudantes do curso de Ciências Contábeis.

\section{Referências}

Álvaro Méndez, J. M. (2002). Avaliar para conhecer examinar para excluir. Porto Alegre: Artmed.

Brasil. Lei ${ }^{\circ} 11.638$, de 28 de dezembro de 2007. (2007). Altera e revoga dispositivos da Lei $n^{\circ} 6.404$, de 15 de dezembro de 1976, e da Lei $n^{\circ} 6.385$, de 7 de dezembro de 1976, e estende às sociedades de grande porte disposições relativas à elaboração e divulgação de demonstrações financeiras. Recuperado em 20 junho, 2017, de http://www.planalto.gov.br/ccivil_03/_ato2007-2010/2007/lei/111638.htm.

Brasil. Ministério da Educação. Resolução CNE/CES no 10, de 16 de dezembro de 2004. (2004) Diretrizes curriculares nacionais para o curso de graduação em Ciências Contábeis. Recuperado em 20 junho, 2017, http://portal.mec.gov.br/cne/arquivos/pdf/rces010_04.pdf. 
Capacchi, M., Moretto, C. F., Vancin, V. \& Padilha, F. A. R. (2007). A prática do ensino contábil no Estado do Rio Grande do Sul: uma análise da grade curricular frente às exigências legais e necessidades acadêmicas. In: CONGRESSO ANPCONT, 1., 2007, Gramado. Anais... Gramado: ANPCONT.

Capacchi, M., Moretto, C. F., Vancin, V. \& Padilha, F. A. R. (2007). A prática do ensino contábil no Estado do Rio Grande do Sul: uma análise da grade curricular frente às exigências legais e necessidades acadêmicas. Anais do Congresso Anpcont, Gramado, RS, Brasil, 1.

Carvalho L. N. \& SALOTTI, B. M. (2013). Adoption of IFRS in Brazil and the Consequences to Accounting Education. Issues in Accounting Education, 28(2), p. 235-242. DOI: http://dx.doi.org/10.2308/ iace-50373.

Conselho Federal de Contabilidade - CFC. (2009). Proposta nacional de conteúdo para o curso de Graduação em Ciências Contábeis. 2a ${ }^{\text {a }}$ ed. revista e atualizada. Brasília: CFC.

Corbucci, P. R. (2007). Desafios da educação superior e desenvolvimento no Brasil. Instituto de Pesquisa Econômica Aplicada (IPEA).

Corrêa, M. D., Antonovz, T. \& Espejo, M. M. S. B. (2009). A percepção dos Alunos sobre a Importância das Disciplinas do Currículo do Curso de Ciências Contábeis: reflexões diante do contexto contemporâneo. Anais Encontro de Ensino e Pesquisa em Administração e Contabilidade, Curitiba, PR, Brasil, 2.

Demo, P. (1998). Conhecimento Moderno: sobre a Ética e Intervenção do Conhecimento. Petrópolis: Vozes.

Doll Jr, W. E. (1997). Currículo: uma perspectiva pós-moderna. Porto Alegre: Artes Médicas.

Ferreira, M. A. (2015). Determinantes do desempenho discente no ENADE em cursos de ciências contábeis. Dissertação de Mestrado, Programa de Pós-Graduação em Ciências Contábeis, Universidade Federal de Uberlândia, Uberlândia, MG, Brasil.

Fouché, J. P. (2013). A renewed call for change in accounting education practices. Int J Edu Sci, 5(2), p. 137150. Recuperado em: http://krepublishers.com/02-Journals/IJES/IJES-05-0-000-13-Web/IJES-052-000-13-Abst-PDF/IJES-05-2-137-13-181-Fouche-J-P/IJES-05-2-137-13-181-Fouche-J-P-Tt.pdf.

Fouché, J. P. (2013). A renewed call for change in accounting education practices. Int JEdu Sci, 5(2), p. 137-150. Recuperado em 20 junho, 2017, de http://krepublishers.com/02-Journals/IJES/IJES-050-000-13-Web/IJES-05-2-000-13-Abst-PDF/IJES-05-2-137-13-181-Fouche-J-P/IJES-05-2-137-13181-Fouche-J-P-Tt.pdf.

Freitas, S. C., Barbosa, I., Galvão J. A. \& Miranda J. M. (2015) Percepção acerca da qualidade e utilidade do relatório de avaliação do ENADE: um estudo na área de negócios. Revista Contemporânea de Contabilidade, 12(27), p. 117-136. Recuperado em 20 junho, 2017, de https://periodicos.ufsc.br/index. php/contabilidade/article/view/2175-8069.2015v12n27p117. DOI: http://dx.doi.org/10.5007/\%x.

Galdino, J. A. \& Soares, S. V. (2013). O Aspecto Generalista ou Especialista da Formação em Ciências Contábeis nas Universidades Públicas da Região Norte do Brasil: uma análise curricular. Anais do Encontro de Ensino e Pesquisa em Administração e Contabilidade, Curitiba, PR, Brasil, 4

Grizendi, J. C. M., Silva, J. A. O. \& Ferreira, V. C. P. A. (2008). Contribuição da Avaliação Continuada para a Melhora do Desempenho Discente: relato de uma experiência. Estação Científica Online, 6.

INEP. (2004). SINAES: Sistema Nacional de Avaliação da Educação Superior: da concepção à regulamentação. 2. ed. Brasília (DF): MEC.

INEP. Conceito Preliminar do Curso - CPC. (2012). Recuperado em 20 junho, 2017, de http://portal.inep. gov.br/educacao-superior/indicadores/cpc.

Jackling, B., Howieson, B. \& Natoli, R. (2012). Some Implications of IFRS Adoption for Accounting Education. Australian Accounting Review, 22, p. 331-340. 
Jackson, P. W. (1990). Life in Classrooms. New York: Teachers College Press.

Jesus, A. R. (2008). Currículo e educação: conceito e questões no contexto educacional. Anais do Congresso Nacional de Educação, Curitiba, PR, Brasil, 8.

Kwiek, M. (2001). The Internationalization and Globalization in Central and East European Higher Education. Society for Research in Higher Education International News, 47, 3-5.

Kumar, R. \& Usunier, J. (2001). Management Education in a Globalizing World Lessons from the French Experience. Management Learning, Sage Publications, 32(3), p. 363-391.

Lagioia, U. C. T., Santiago, H. L. F., Gomes, R. B. \& Ribeiro Filho, J. F. (2007). Uma investigação sobre as expectativas dos estudantes e o seu grau de satisfação em relação ao curso de Ciências Contábeis. Revista Contemporânea de Contabilidade, 4(8), p. 121-138.

Martins, G. A. \& Theóphilo, C. R. (2007). Metodologia da investigação cientifica para ciências sociais aplicadas. São Paulo: Atlas.

MEC - Ministério da Educação. (2013). Sistema Nacional de Avaliação da Educação Superior (SINAES). Recuperado em 12 maio, 2015, de: http://portal.mec.gov.br/index.php/?id=12303\&option=com_ content.

Miranda, G. J.; Lemos, K. C. S.; Oliveria, A. S. \& Ferreira, M. A. (2015). Determinantes do Desempenho Acadêmico na Área de Negócios. Revista Meta: Avaliação, 7(20), p. 175 - 209.

Moreira, A. F. B. \& Silva T. T. (org.). (1997). Currículo, cultura e sociedade. 2a . ed. São Paulo: Cortez.

Oliveira, K. G, Silva, V. R., Miranda, G. J. \& Tavares, M. (2015). Análise comparativa entre os currículos das IFES brasileiras e a proposta curricular do conselho federal de contabilidade. Anais do Congresso Anpcont, Curitiba, PR, Brasil, 9.

Paola, M. D. (2009). Does Teacher Quality Affect Student Performance? Evidence From an Italian University. Bulletin of Economic Research. 61(4), p. 353-377.

Peck, L. R. \& Gorzalski, L. M. (2009). An evaluation use framework and empirical assessment. Journal of MultiDisciplinary Evaluation, 6(12), p. 139-156. DOI: http://dx.doi.org/10.5007/2175-8069.2015v12n27pl17.

Pires, C. B. \& Ott, E. (2008). Estrutura curricular do curso de Ciências Contábeis no Brasil versus Estruturas curriculares propostas por organismos internacionais. Anais do Congresso USP de Controladoria e Contabilidade, São Paulo, SP, Brasil, 8.

Polidori, M. M., Marinho-Araujo, C. M., Barreyro \& G. B. (2006). SINAES: perspectivas e desafios na avaliação da educação superior brasileira. Ensaio. 14(53), p. 425-436.

Porter, B. \& Carr, S. (1999). From Strategic Plan to Practical Realities: Developing and Implementing a Zero-Based Accounting Curriculum. Issues in Accounting Education, 14(4). DOI: http://dx.doi. org/10.2308/iace.1999.14.4.565.

Preskill, H. \& Caracelli, V. (1997). Current and developing conceptions of use: Evaluation use tig survey results. Evaluation Practice, 18(3), p. 209-225.

R Development Core Team. (2015). R: A language and environment for statistical computing. R Foundation for Statistical Computing, Vienna, Austria. Recuperado em 20 junho, 2017, de: http://www.R-project.org/.

Ribeiro, V. N. C. (2010). Planejamento Educacional: organização de estratégias e superação de rotinas ou protocolo institucional? Revista Científica Online, 4(1), p. 1-12. Recuperado em 20 junho, 2017, http:// www.faculdadeatenas.edu.br/arquivos/NucleoIniciacaoCiencia/REVISTAS/REVIST2010/10.pdf.

Richardson, R. J. (2011). Pesquisa Social: métodos e técnicas. 3ª ed. São Paulo: Atlas. 
Riccio, E. L. \& Sakata, M. C. G. (2004). Evidências da globalização na educação contábil: estudo das grades curriculares dos cursos de graduação em universidades brasileiras e portuguesas. Revista Contabilidade \& Finanças, 15(35), p. 35-44. DOI: http://dx.doi.org/10.1590/S1519-70772004000200003.

Rodrigues, B. C. O. \& Miranda, G. J. (2013). Concursos para contador: quais conteúdos vêm sendo priorizados? Anais do Congresso Brasileiro de Custos, Uberlândia, MG, Brasil, 20.

Rojas-Rojas, W. \& Giraldo-Garcés, G. A. (2015). Humanidades y formación contable: una relación necessária para otear una reorientación de la profesión contable. Cuadernos de Contabilidad, 16(40), p. 261-276. DOI: http://10.11144/Javeriana.cc16-40.hfcr.

Sacristán, J. G. (2000). Currículo: Uma Reflexão Sobre a Prática. Tradução de Ernani Ferreira da Fonseca Rosa. Porto Alegre: Artmed.

Silva, T. T. (1996). Identidades terminais: as transformações na política da pedagogia e na pedagogia da política. Petrópolis: Vozes.

Silva, V. R. (2016). ENADE e fluxo curricular nos cursos de graduação em ciências contábeis no Brasil. Dissertação de Mestrado, Programa de Pós-Graduação em Ciências Contábeis, Universidade Federal de Uberlândia, Uberlândia, MG, Brasil.

Silva, V. R \& Miranda, G. J. (2016). ENADE e fluxo curricular nos cursos de graduação em ciências contábeis no Brasil. Revista Universo Contábil, 12(4), p. 30-47.

Soares, V. S., Borgert, A., Pfitscher, E. D. \& Will A. R. (2012). Currículo dos cursos de Ciências Contábeis das Universidades Federais da Região Sul do Brasil: Formação especialista ou generalista. Enfoque: Reflexão Contábil, 31, p. 7-21. DOI: http://10.4025/enfoque.v31i2.13997.

Taylor, P. (1970). How teachers plan their courses. Studies in curriculum planing. Londres. NFER.

Vasconcelos, C. S. (2008). Planejamento: projeto de ensino-aprendizagem e projeto político-pedagógico - elementos metodológicos para elaboração e realização, 18ª ed, São Paulo: Libertad Editora.

Veiga, I. P. A. (2003). Inovações e Projeto Político-Pedagógico: uma relação regulatória ou emancipatória? Cad. Cedes, 23(61), p. 267-281.

Wallace, M. (2003). Managing the Unmanageable? Coping with Complex Educational Change. Educational Management \& Administration, 31(1), p. 9-29.

Worthen, B. R.; Sander. J. R.; Fitzpatrick, J. L. Avaliação de programas: concepções e práticas. São Paulo: EDUSP, 2004. 